\title{
Kinetoplastids: related protozoan pathogens, different diseases
}

\author{
Ken Stuart, ${ }^{1}$ Reto Brun, ${ }^{2}$ Simon Croft, ${ }^{3}$ Alan Fairlamb, ${ }^{4}$ Ricardo E. Gürtler, ${ }^{5}$ Jim McKerrow, ${ }^{6}$ \\ Steve Reed, ${ }^{7}$ and Rick Tarleton ${ }^{8}$
}

\begin{abstract}
${ }^{1}$ Seattle Biomedical Research Institute and University of Washington, Seattle, Washington, USA. ${ }^{2}$ Swiss Tropical Institute, Basel, Switzerland. ${ }^{3}$ Department of Infectious and Tropical Diseases, London School of Hygiene and Tropical Medicine, London, United Kingdom. ${ }^{4}$ School of Life Sciences, University of Dundee, Dundee, United Kingdom. 5Departamento de Ecología, Genética y Evolución, Universidad de Buenos Aires, Buenos Aires, Argentina. ${ }^{6}$ Sandler Center for Basic Research in Parasitic Diseases, UCSF, San Francisco, California, USA. ${ }^{7}$ Infectious Disease Research Institute, Seattle, Washington, USA. ${ }^{8}$ Center for Tropical and Emerging Global Diseases, University of Georgia, Athens, Georgia, USA.
\end{abstract}

\begin{abstract}
Kinetoplastids are a group of flagellated protozoans that include the species Trypanosoma and Leishmania, which are human pathogens with devastating health and economic effects. The sequencing of the genomes of some of these species has highlighted their genetic relatedness and underlined differences in the diseases that they cause. As we discuss in this Review, steady progress using a combination of molecular, genetic, immunologic, and clinical approaches has substantially increased understanding of these pathogens and important aspects of the diseases that they cause. Consequently, the paths for developing additional measures to control these "neglected diseases" are becoming increasingly clear, and we believe that the opportunities for developing the drugs, diagnostics, vaccines, and other tools necessary to expand the armamentarium to combat these diseases have never been better.
\end{abstract}

\section{Introduction}

Kinetoplastids are a group of flagellated protozoans that are distinguished by the presence of a DNA-containing region, known as a "kinetoplast," in their single large mitochondrion. Although the different kinetoplastid pathogens have a similar genomic organization and similar cellular structures and all undergo morphological changes during their life cycles, these flagellated protozoans cause distinct human diseases and are transmitted by different insect vectors (Table 1). The most common human diseases caused by kinetoplastids include human African trypanosomiasis (HAT; also known as African sleeping sickness), which is caused by infection with two of the three subspecies of Trypanosoma brucei; Chagas disease, which is caused by infection with Trypanosoma cruzi; and various forms of leishmaniasis, which are caused by infection with different species of Leishmania (1). Half a billion people, primarily in tropical and subtropical areas of the world, are at risk of contracting these diseases, and it is estimated that more than 20 million individuals are infected with the pathogens that cause them, resulting in extensive suffering and more than 100,000 deaths per year.

Much of the cellular biology of the different kinetoplastids is very similar. For example, they are all motile protozoans with a single flagellum that originates near their large single mitochondrion and emanates from a pocket in the cell membrane, where endocytosis also occurs; their peroxisomes are modified to perform glycolysis and are therefore known as "glycosomes;" their cell membrane is underlain with a sheet of microtubules and is highly decorated with species-specific molecules that are critical for their survival; they typically grow asexually, and although

Nonstandard abbreviations used: CL, cutaneous leishmaniasis; HAT, human African trypanosomiasis; ML, mucosal leishmaniasis; VL, visceral leishmaniasis; VSG, variant surface glycoprotein.

Conflict of interest: K. Stuart serves as an advisor for two projects funded by the Bill and Melinda Gates Foundation, for which he receives compensation and/or expense reimbursement. S. Reed has received funding from the Bill and Melinda Gates Foundation. All other authors have declared that no conflict of interest exists.

Citation for this article: J. Clin. Invest. 118:1301-1310 (2008). doi:10.1172/JCI33945 sexual recombination has been shown for T. brucei, inferred for T. cruzi, and might occur in some species of Leishmania, it is not obligate in any; and they divide by binary fission during which their nucleus does not undergo membrane dissolution or chromosome condensation. Despite these similarities, which are not surprising given that of the more than 8,000 genes in the genome of each kinetoplastid there are more than 6,000 orthologs in common, the diseases that they cause are very distinctive. Understanding the differences between these human disease-causing pathogens at the genetic, molecular, and cellular levels might provide new approaches to the development of diagnostics, vaccines, drugs, and other tools needed to combat these diseases. Achieving these goals is more feasible now due to a combination of new knowledge of parasite genomes and biochemistry, new insight into host immune responses, and the injection of substantial philanthropic support. These recent advances together with the knowledge from epidemiological studies could complement surveillance, vector control, and other public health efforts to provide for optimum control, and hopefully the elimination, of these diseases.

\section{The diseases, their pathogenesis, and their diagnosis}

$H A T$. About 50 million people live in HAT transmission areas. Its incidence resurged in the 1990s due to civil unrest and a lack of awareness of the disease, with major flare-ups in Angola, Democratic Republic of the Congo, Uganda, and Sudan. Mortality rates are uncertain, but prevalence was estimated to be about 500,000 cases in 1998, of which only 40,000 were reported. These rough estimates reflect the rural and focal nature of the disease as well as under-surveillance. Subsequent decreases in incidence seem to be due to greater political stability and funding of surveillance and control programs as well as pharmaceutical company drug donations, all of which helped reduce the reported new cases of HAT to 17,600 in 2004 (2).

HAT is fatal if left untreated (1). The first stage of the disease (the hemolymphatic stage) is accompanied by fever, headache, adenopathy, joint pain, and pruritus. Rapid parasite growth is countered by host immune responses, but parasite antigenic varia- 


\section{Table 1}

The kinetoplastid diseases

\begin{tabular}{|c|c|c|c|}
\hline & HAT & Chagas disease & The leishmaniases \\
\hline $\begin{array}{l}\text { Principal disease forms } \\
\text { or stages }\end{array}$ & $\begin{array}{l}\text { Early (hemolymphatic) stage, } \\
\text { late (CNS) stage }\end{array}$ & $\begin{array}{l}\text { Acute phase, indeterminant phase, } \\
\text { chronic phase (cardiac and } \\
\text { digestive forms) }\end{array}$ & VL, MCL, CL \\
\hline Causative organisms & T.b. gambiense, T.b. rhodesiense & T. cruzi & $\begin{array}{l}\text { 21 Leishmania spp., e.g., L. donovani } \\
\text { (VL), L. braziliensis (MCL), L. major (CL) }\end{array}$ \\
\hline Host cell/tissue & $\begin{array}{l}\text { Extracellular, in blood, lymph, } \\
\text { cerebral spinal fluid, and } \\
\text { intercellular spaces }\end{array}$ & $\begin{array}{l}\text { Intracellular, in cytoplasm of heart, } \\
\text { smooth muscle, gut, CNS, and } \\
\text { adipose tissue cells }\end{array}$ & $\begin{array}{l}\text { Intracellular, in phagolysosomes } \\
\text { of macrophages }\end{array}$ \\
\hline $\begin{array}{l}\text { Vectors of medical } \\
\text { importance }\end{array}$ & $\begin{array}{l}\text { Tsetse flies ( } \sim 20 \text { Glossina spp.) } \\
\text { (palpalis group, T.b. gambiense; } \\
\text { morsitans group, T.b. rhodesiense) }\end{array}$ & $\begin{array}{l}\text { Reduviid bugs ( 12/ 138 } \\
\text { Triatominae spp.) (Triatoma, } \\
\text { Rhodnius, and Panstrongylus spp.) }\end{array}$ & $\begin{array}{l}\text { Phebotomine sandflies ( } 70 \text { spp.) } \\
\text { (Phlebotomus spp. in Old World, } \\
\text { Lutzomyia spp. in New World) }\end{array}$ \\
\hline Transmission & $\begin{array}{l}\text { Infected fly bite, congenital (rare), } \\
\text { blood transfusion (rare) }\end{array}$ & $\begin{array}{l}\text { Contamination by feces of infected } \\
\text { bugs (e.g., at bite site, in mucous } \\
\text { membranes, in food or drink), } \\
\text { blood transfusion, congenital, } \\
\text { organ transplantation (rare) }\end{array}$ & Infected fly bite \\
\hline Geographic distribution & $\begin{array}{l}\text { Sub-Saharan Africa } \\
\text { ( } 20 \text { countries })\end{array}$ & $\begin{array}{l}\text { South and Central America } \\
\text { (19 countries) }\end{array}$ & $\begin{array}{l}\text { South and Central America, Europe, Africa, } \\
\text { Asia (88 endemic countries) }\end{array}$ \\
\hline Population at risk & 50 million & 100 million & 350 million \\
\hline Infected & $70,000-80,000^{A}$ & 8-11 million & 12 million \\
\hline Health burden (DALYs) & 1.5 million & 0.7 million & 2.1 million \\
\hline Deaths (per annum) & $\sim 30,000$ & 14,000 & $51,000(\mathrm{VL})$ \\
\hline $\begin{array}{l}\text { Prevention and control } \\
\text { measures }\end{array}$ & $\begin{array}{l}\text { Active surveillance of at-risk } \\
\text { populations, drug treatment of } \\
\text { infected patients, tsetse fly traps, } \\
\text { residual insecticides, sterile insect } \\
\text { technique, tsetse habitat } \\
\text { destruction to inhibit reinvasion }\end{array}$ & $\begin{array}{l}\text { Treatment of homes with residual } \\
\text { insecticides, blood donor screening, } \\
\text { drug treatment for acute, early } \\
\text { indeterminate and congenital cases, } \\
\text { better housing (plastered walls and } \\
\text { metal roof replacing adobe-walled, } \\
\text { thatch-roofed dwellings) }\end{array}$ & $\begin{array}{l}\text { Surveillance and treatment of VL cases; } \\
\text { reservoir (dog) control (VL); } \\
\text { treatment of homes with residual } \\
\text { insecticides; insecticide-treated bed } \\
\text { nets, fabrics, and dog collars; live } \\
\text { vaccination ("leishmanization," CL) }\end{array}$ \\
\hline
\end{tabular}

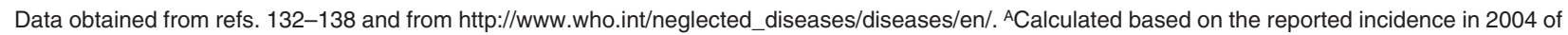
$\sim 18,000$ cases identified from 3.3 million people under active surveillance, assuming 50 million at risk (8). DALY, disability-adjusted life year; MCL, mucocutaneous leishmaniasis.

tion enables immune evasion, resulting in waves of parasitemia. The second stage of the disease (the CNS stage) is accompanied by severe neurological symptoms including mental, sensory, and sleep anomalies. HAT occurs in geographic foci across sub-Saharan Afri$\mathrm{ca}$ in areas populated by tsetse flies. Trypanosoma brucei gambiense causes more chronic disease in central and western regions of subSaharan Africa, whereas Trypanosoma brucei rhodesiense causes more acute disease in the eastern and southern regions. These pathogens are morphologically identical to each other and to the nonhuman pathogen Trypanosoma brucei brucei but can be distinguished by the genes encoding serum resistance-associated (SRA) protein and T.b. gambiense-specific glycoprotein, which are found only in the genomes of T.b. rhodesiense and T.b. gambiense, respectively; T.b. brucei has neither $(3,4)$. Over 20 species and subspecies of tsetse flies (Glossina spp.) transmit these parasites, but only approximately 1 per 1,000 flies exhibit the mature salivary gland infection necessary to transmit the pathogen to humans. Trypanosomes enter the fly when it takes a meal of protozoan-containing blood from an infected human or animal and, over a period of four weeks, undergo morphological and physiological transformations in the alimentary tract and salivary glands, where they become infective (Figure 1). The specific pathogenesis of HAT, especially the second stage of the disease, is not well characterized but might entail immune processes and bioactive pathogen molecules.
Current tools for diagnosing HAT are not completely satisfactory, since those for the more dangerous second stage of the disease are invasive and insensitive, whereas those for the first stage of disease do not discriminate T. brucei subspecies and even detection of the presence of parasites in fresh blood or lymph node aspirates from patients by microscopy, which can signal the first stage of the disease, is not readily translated into the field. The card agglutination test for trypanosomiasis is based on a frequent variant surface glycoprotein (VSG) expressed by T.b. gambiense and does not require a microscope (5), but there is no comparable test for T.b. rhodesiense and the PCR-oligochromatography molecular dipstick test for both HAT-causing T. brucei subspecies (6) is not in general use, perhaps due to availability or cost. The discovery of the SRA gene (7) led to diagnostics of T.b. rhodesiense based on molecular technologies and its discrimination from T.b. gambiense (3). This diagnostic is now in use in the field, for example, to identify human infective trypanosomes in domestic animals in Uganda (8). Although the above methods detect the first stage of disease, discriminating the second stage of disease is crucial for selecting the appropriate chemotherapy. Parasitological confirmation is typically required before treatment is initiated, since drug toxicity is high. Currently, cerebrospinal fluid, the collection of which is difficult and introduces risk to the patient in the field, is examined for parasites and/or elevated white blood cells and IgM 


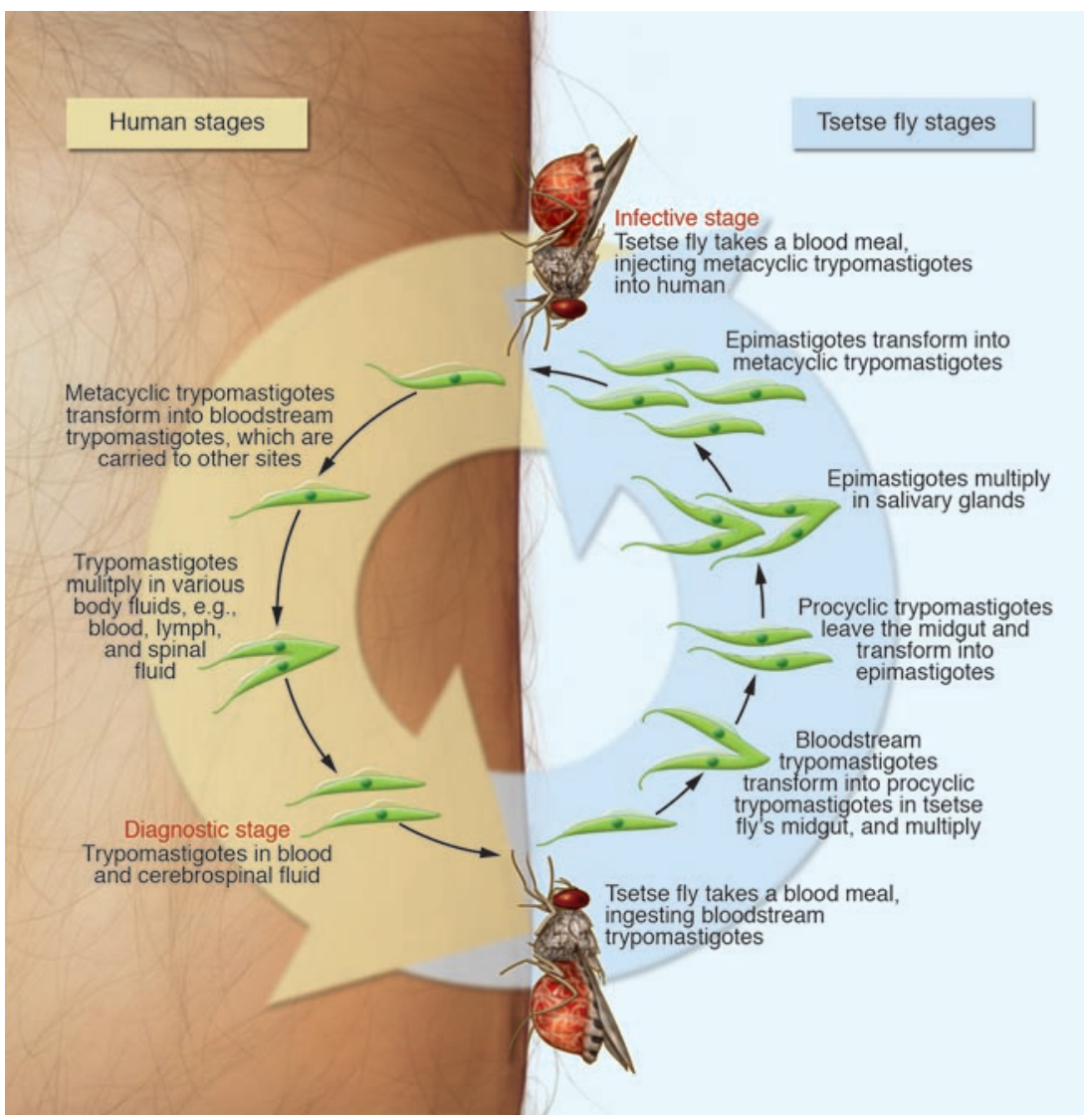

\section{Figure 1}

Life cycle of $T$. brucei. HAT is caused by infection with the T.b. rhodesiense or T.b. gambiense subspecies. Over 20 species and subspecies of tsetse flies transmit these parasites, but only approximately 1 per 1,000 flies has the mature salivary gland infection that is necessary to transmit the parasite to humans. Trypanosomes enter the fly when it takes a meal of parasite-containing blood from an infected human or animal and, over a period of four weeks, undergo morphological and physiological transformations in the alimentary tract and in the salivary glands, where they become infective. During a blood meal on the mammalian host, an infected tsetse fly injects parasites into skin tissue. The parasites pass via the lymphatic system into the bloodstream, which carries them throughout the body. The parasites continue to replicate by binary fission. In late-stage disease the parasites invade the CNS and reside in the cerebrospinal fluid and intercellular spaces. Figure modified with permission from Alexander J. da Silva and Melanie Moser, Centers for Disease Control Public Health Image Library.

levels (9). The low numbers of trypanosomes in blood and cerebrospinal fluid necessitate concentration by centrifugation or anion exchange chromatography, two methods that have been adapted to the field (10).

Chagas disease. Chagas disease is prevalent throughout the Americas. It mostly affects people whose housing provides a habitat for the Triatominae insects, commonly called "kissing bugs," which act as a vector for the disease-causing parasite T. cruzi. There are many domestic and wild mammal reservoirs of T. cruzi. Infection with $T$. cruzi can also result from blood transfusion (11), organ transplantation (12), vertical transmission (13), and by ingestion of contaminated food or drink (14).

Chagas disease is the result of persistent infection with T. cruzi and complex interactions between the pathogen and host immune response, which, in the absence of immune system dysfunctions (e.g., in individuals with AIDS), results in very low parasite numbers but rarely elimination of the infection in this chronic or indeterminate phase (15) (Figure 2). Nondividing transmissible extracellular trypomastigotes infect and replicate as amastigotes in cells of multiple organs and tissues, including the heart, gut, CNS, smooth muscle, and adipose tissue (16-18). An estimated $30 \%$ of individuals infected with T. cruzi develop clinical Chagas disease, which manifests as cardiac disease or pathological gut enlargement, decades after the initial infection. Although an autoimmune etiology was initially hypothesized, the continuous immune assault on persistent parasites is likely to be the primary cause of cumulative tissue damage in chronic Chagas disease.

The current diagnostics for Chagas disease are inadequate yet crucial for identifying infected individuals as well as monitoring treatment and other interventions $(19,20)$. Direct detection of parasites after the acute stage of infection is very difficult due to their low numbers. Multiple serological tests using different platforms (e.g., ELISA, indirect immunofluorescence, and indirect hemagglutination) are routinely used to attempt to obtain a consensus result. However, the infection status of those positive in only one test is inconclusive (21), and multiple tests on individuals with detectable parasites can give negative results (22). Thus, current tests are inadequate for monitoring treatment efficacy and other interventions. New tests need to be developed to inform policy development for treatment and control strategies.

The Leishmaniases. There are more than 21 species of Leishmania that cause various diseases ranging from self-healing cutaneous leishmaniasis (CL) to debilitating and lethal (if untreated) visceral leishmaniasis (VL; also known as kala-azar) (23). Less frequent but devastating forms of the disease include mucosal leishmaniasis (ML), which is disfiguring (24); diffuse CL, which causes numerous nodular lesions (25); and post kala-azar dermal leishmaniasis, which occurs as a sequelae to VL (26). VL is caused by infection with either Leishmania infantum or Leishmania donovani and has an estimated global incidence of 200,000-500,000 cases; CL is caused by infection with any one of several different Leishmania spp. and has a prevalence of more than 5 million cases worldwide (http://who.int/tdr). However, most L. infantum infections are subclinical and develop to disease only if immune responses are depressed (27-29). Leishmania major and Leishmania mexicana lesions usually self cure within 3-12 months, leaving deep scarring, whereas Leishmania tropica and Leishmania braziliensis lesions, which are also cutaneous, take up to 18 months to 


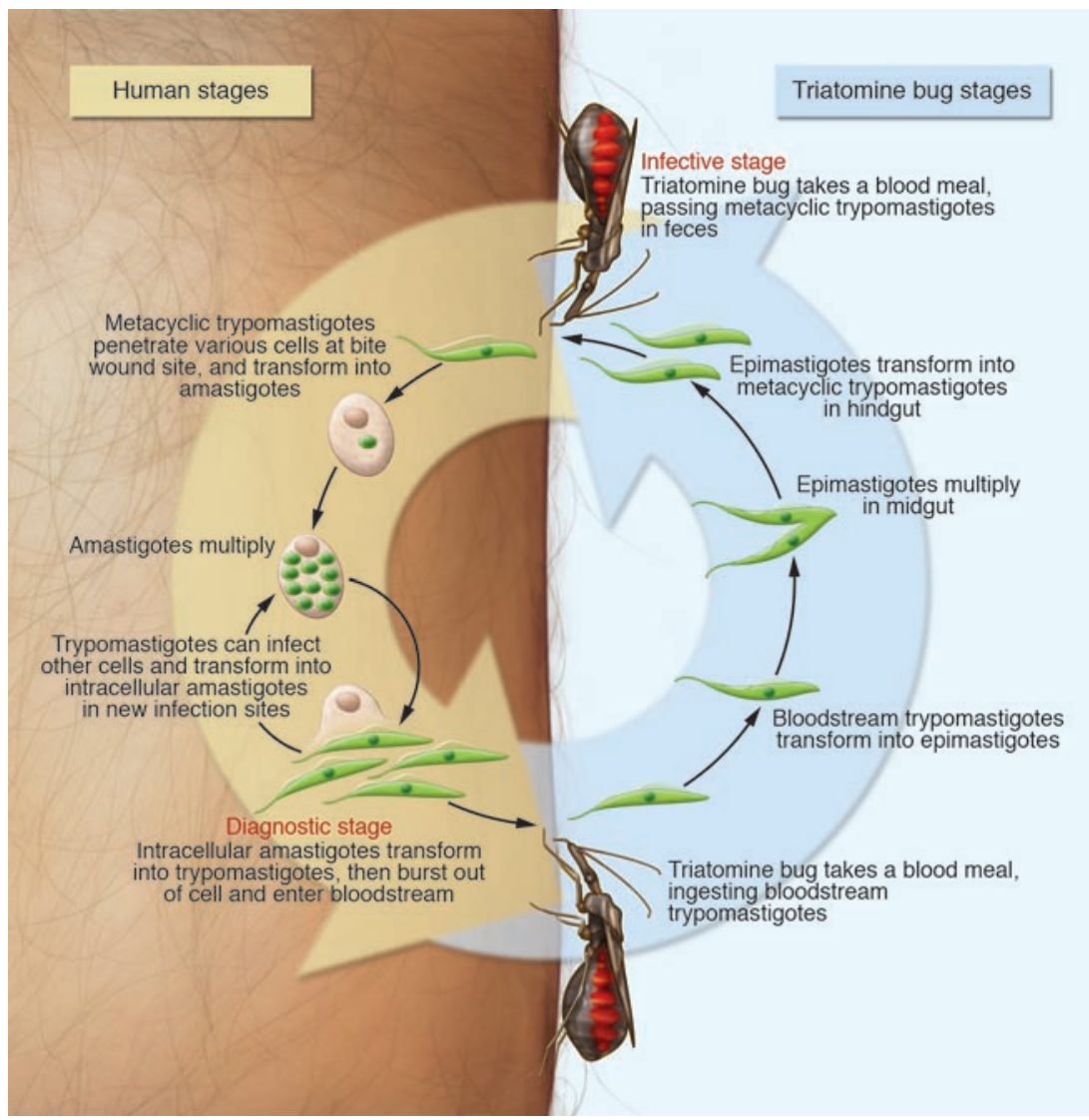

\section{Figure 2}

Life cycle of $T$. cruzi. Persistent infection with $T$. cruzi causes Chagas disease. The parasite is transmitted to humans by infected blood-sucking Triatominae insects, which deposit trypomastigotes in their feces during feeding. The trypomastigotes enter the wound and invade nearby cells, within which they differentiate into intracellular amastigotes that multiply by binary fission. The amastigotes differentiate into trypomastigotes, which are released into the bloodstream and infect cells of multiple organs and tissues, including the heart, gut, CNS, smooth muscle, and adipose tissue and once again become amastigotes. The Triatominae insects become infected when they take a parasitecontaining blood meal from an infected human or animal. The trypomastigotes undergo morphological and physiological transformations in the midgut of the vector and differentiate into infective trypomastigotes in the hindgut. Image modified with permission from Alexander J. da Silva and Melanie Moser, Centers for Disease Control Public Health Image Library.

cure and in some cases can develop into the severely disfiguring ML disease state that is difficult to cure.

Leishmania parasites invade mammalian macrophages by receptor-mediated endocytosis, for example, via complement receptors that are cleaved by parasite proteases (Figure 3). They multiply in the low-pH, amino acid-rich endolysosomes, to which their metabolism and nutrition are adapted (30). L. donovani and L. infantum, which infect cells found in lymphoid tissues, including spleen, lymph nodes, and bone marrow, inhibit an effective immune response to the parasite. Parasite lipophosphoglycans reduce the activity of PKC and protein tyrosine kinases (PTKs) in macrophages that they have infected, leading to attenuated IFN- $\gamma$ induced immune activation (31). Broader effects on the immune system include reduced levels of IL-12 produced by macrophages $(32,33)$ and elevated amounts of TGF- $\beta$ and IL-10 produced by macrophages and $\mathrm{T}$ cells (34). The resulting immunosuppression can lead to secondary respiratory infections that can be fatal in individuals with VL. By contrast, patients with CL, in whom the pathogen is largely restricted to the skin and is not found in lymphoid tissues, do not become immunosuppressed and generally develop a curative immune response.

The diagnosis of CL and ML usually employs microscopic detection of organisms in the lesions and skin tests, which consist of intradermal injection of whole or lysed promastigote forms of the pathogen followed by measuring local induration at the injection site $48-72$ hours later $(35,36)$. Organisms can be seen in splenic and bone marrow aspirates and can be cultured from the blood of patients with VL, but the high levels of serum antibody specific for parasite antigens allow serological diagnosis of VL using
ELISA. Advances in antigen discovery and serological diagnosis have resulted in antibody-based tests for VL that can be used in the field, including a direct agglutination test (DAT) and a lateral flow assay (LFA), both of which detect the presence of the K39 repeat antigen (37) that is expressed by both species of Leishmania that cause VL and, to a lesser extent, by other species. The DAT (Royal Tropical Institute) is sensitive and specific but requires substantial laboratory incubation, whereas the Kalazar Detect rapid test (InBios International Inc.) produces results in a few minutes. The rK39-LFA is highly sensitive in patients in India, Bangladesh, and Nepal, but it is less sensitive in patients in Africa, perhaps due to heterogeneity in the species of Leishmania that cause VL; however, its sensitivity exceeds that of microscopic detection of parasites. The serological sensitivity of defined antigens is useful for diagnosis in individuals with VL who are also infected with HIV and for determining whether individuals with VL, whose titers of antibody specific for these antigens are falling, have eliminated the causative pathogen (38). An accurate test of cure would be useful for evaluating new therapies. Other promising diagnostics are detection of antigen in the urine by latex agglutination (KAtex; Kalon Biological Ltd.) and detection of modified sialic acid residues on erythrocytes (due to the production of immature erythrocytes by infected bone marrow; Zephyr Biomedical) (39). Molecular diagnosis of leishmaniasis includes PCR detection of Leishmania spp. DNA (40). Field-adaptable systems include Liat Analyzer (IQuum Inc.), a simplified PCR assay that uses a colorimetric detection system and a portable instrument that can extract and amplify DNA as well as detect the PCR product. Measurement of T cell responses to antigens expressed by Leishmania spp. is useful for verifying CL and 


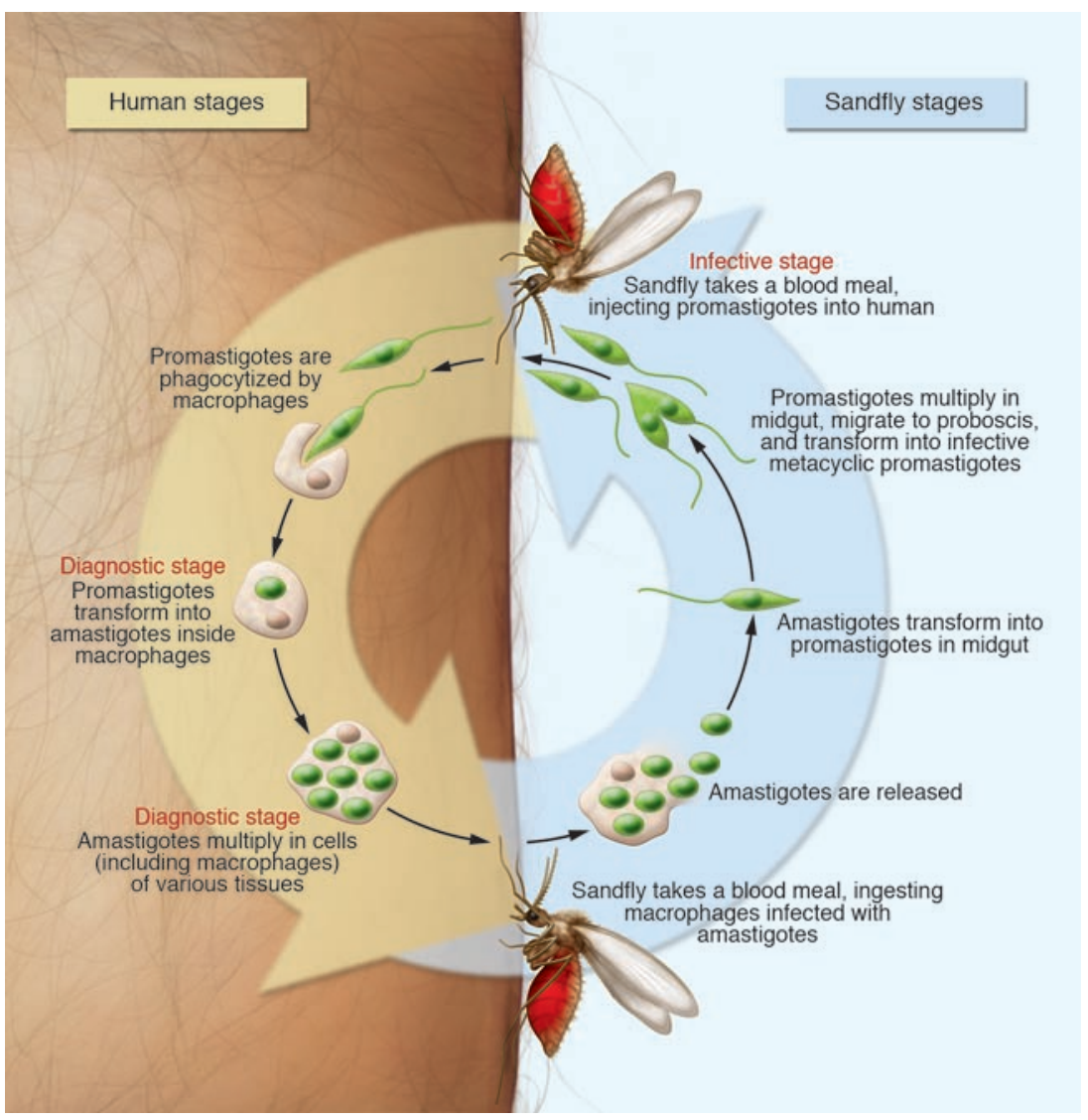

\section{Figure 3}

Life cycle of Leishmania spp. Infection with different species of Leishmania causes distinct forms of leishmaniasis. For example, VL is caused by infection with either $L$. infantum or $L$. donovani; whereas $C L$ is caused by infection with any one of several different Leishmania spp. Sandflies are the vectors that transmit the disease-causing protozoan parasites, injecting infective promastigotes when they take a blood meal. The parasites invade mammalian macrophages by receptor-mediated endocytosis, where they transform into amastigotes that multiply by binary fission. Sandflies become infected by ingesting infected cells when they take a meal of parasite-containing blood from an infected human or animal. The amastigotes transform into promastigotes and develop in the gut into metacyclic promastigotes that are infective to humans. Figure modified with permission from Alexander J. da Silva and Melanie Moser, Centers for Disease Control Public Health Image Library.

subclinical VL, in which cellular immune responses are strong. No skin test that discriminates between Leishmania spp., or that discriminates Leishmania from other kinetoplastids, is available, but a process to prepare a standardized reagent has been developed (41, 42) and a prototype in vitro assay to measure $\mathrm{T}$ cell responses to Leishmania spp. has been developed by Cellestis (43).

\section{Interventions: treatment, vector control, and the potential for vaccine design}

$H A T$. Treatment of HAT currently relies on five drugs, all of which have adverse effects and problems of efficacy, administration, and compliance $(44,45)$. Suramin and pentamidine (Pentacarinat; Sanofi-Aventis) are used to treat the first stage of disease caused by infection with T.b. rhodesiense and T.b. gambiense, respectively. Both drugs have the drawback that they must be administered parenterally (suramin i.v. and pentamidine i.m.), but efficacy is high and adverse effects are moderate. Two drugs, both of which are active against the first stage of HAT, are approved for the treatment of the second stage of disease. Melarsoprol is effective against second-stage HAT caused by both T.b. rhodesiense and T.b. gambiense, and eflornithine (Ornidyl; Sanofi-Aventis) is only active for second-stage HAT caused by T.b. gambiense. The arsenical melarsoprol is administered i.v. and has severe adverse reactions that can be life threatening. Furthermore, the number of treatment failures following its administration is increasing, due to drug resistance or other unknown factors (46). Pharmacokinetic studies on melarsoprol (47) led to the treatment regimen being changed to a 10 -day course rather than the 21 - to 35 -day course previously followed, thus improving patient compliance and reducing hospi- tal costs (48). Eflornithine, a polyamine biosynthesis inhibitor, is registered for cases of HAT caused by infection with T.b. gambiense that are unresponsive to treatment with melarsoprol. It is administered over 14 days as four daily i.v. infusions and has less severe adverse effects than melarsoprol. However, administration of 56 i.v. infusions presents a logistical challenge, especially in resourcepoor rural settings. Clinical trials are ongoing using eflornithine in combination with nifurtimox, a drug that has limited efficacy when used alone, to shorten and simplify the course of eflornithine treatment. In addition, a combination of melarsoprol and nifurtimox has proven to be effective in cases of second-stage HAT that are either refractory to treatment with melarsoprol alone or in situations where ornithine is unavailable (49).

Tsetse fly control programs are using insecticides, traps, and sterile insects to eliminate the flies that transmit the HAT-causing T. brucei subspecies to thereby reduce pathogen transmission and disease (http://www.africa-union.org/PATTEC/home.htm). Effective and economic tsetse control measures include the use of insecticides on cattle and for ground and aerial spraying $(50,51)$. The seeking of patients and treatment of infected persons by mobile teams are also key ways to control infection with T.b. gambiense, since humans are the main reservoir of this pathogen. Animal screening is used to control infection with T.b. rhodesiense, since wild and domestic animals are the crucial reservoirs. Chemoprophylaxis is not recommended due to drug toxicity and the relatively low risk of infection. Development of a vaccine for HAT is highly unlikely because these parasites make many thousands of antigenic variants by alternate expression and recombination of a repertoire of approximately 1,000 VSG-encoding genes, enabling them to evade the immune response. 
Chagas disease. Despite advances in understanding the biology of T. cruzi, only the nitrofuran derivative nifurtimox and the nitroimidazole benznidazole are currently available for treatment of Chagas disease. Both are administered orally but have long treatment courses ( $\geq 60$ days) and side effects (52), and there is variation in the sensitivity of the parasite to the drugs. Benznidazole shows efficacy against the indeterminate phase of infection in children (53). Observational studies have demonstrated the efficacy of benznidazole as a treatment for adults with Chagas disease who have been infected with the parasite for a long time (54-56), but the lower tolerance for drug side effects (52) in adults and the absence of randomized, placebo-controlled studies has adversely affected the frequency of use in adults. Certain antifungal triazoles and protease inhibitors have shown potential in experimental models of infection with T. cruzi (57-59), and late preclinical tests, lead optimization, and good manufacturing practice formulation of these drug leads in preparation for phase I clinical trials are in progress. The reduced transmission of Chagas disease due to intensified vector control in some regions has enhanced the focus on evaluation of drugs against indeterminate and early chronic phase disease.

Insecticidal spraying of houses in the Southern Cone of South America (the southern most areas of South America, below the Tropic of Capricorn) (60) dramatically reduced transmission of T. cruzi in these areas. Although highly successful at eliminating domestic Triatoma infestans, the spraying had limited impact on T. infestans in peridomestic sites and on other vector species (61), and insecticide-resistant strains of T. infestans have emerged (62). Advances in the understanding of infection ecology and disease transmission (63) and the use of geographic information systems (GISs) and low-tech transmission control tools (e.g., insecticide-treated bed nets [ref. 64] and dog collars [ref. 65]) are promising for vector control. Effective disease control requires integrated sustainable programs that are customized to local environmental and sociocultural conditions and deployable at the village and regional levels.

Substantial progress has been made in understanding the types of immune responses that are crucial for control of infection with T. cruzi and in identifying the targets of those responses, information that is crucial if effective vaccines are to be developed (66). Proteins encoded by the trans-sialidase, mucin, and mucin-associated surface protein (MASP) gene families (each with 1,000 or more members) are prime targets of immune responses, but are problematic vaccine candidates, given their strain-to-strain variation (67). Testing a prophylactic vaccine for an infection that is difficult to document and is rarely detected until years, or even decades, after the initial infection also presents formidable practical and ethical issues. More innovative vaccine approaches, for example, the vaccination of companion animal reservoirs (68) and the development of therapeutic vaccines for individuals chronically infected with T. cruzi, deserve exploration.

Leishmaniasis. The standard drugs for the treatment of both VL and $\mathrm{CL}$ are the pentavalent antimonials, sodium stibogluconate and meglumine antimoniate. The introduction of generic brands has reduced costs. However, they require courses of 28 days of parenteral administration (either i.m. or i.v.), have known toxicities, and are almost obsolete for the treatment of VL in India due to the emergence of drug-resistant parasites (69). The antibiotic amphotericin B, previously a second-line drug, has moved to the forefront of treatment in India due to this resistance to antimonials. Of a range of amphotericin B lipid formulations developed for the treatment of systemic mycoses, the liposomal formulation AmBisome has proved to be the most effective treatment for VL, and a single dose of $5 \mathrm{mg} / \mathrm{kg}$ cured $90 \%$ of patients in India (70). However, even at a WHO-negotiated cost, high prices are projected to limit the use of this treatment (71). Paromomycin, an aminoglycoside, has efficacy as a topical treatment for CL and as a parenteral drug (administered i.m.) for VL, for which it was registered in India in 2006 following successful clinical trials (72-74). Its efficacy was essentially equivalent to that of amphotericin B but there were more adverse events (6\% versus $2 \%$ ) (72). Miltefosine, a phospholipid derivative and the first oral treatment for VL (75), is effective against CL (76) and was registered for these indications in India and Colombia in 2002 and 2005, respectively. However, its use is limited by potential teratogenicity.

Development of vaccines to protect against leishmaniasis seems feasible, in part because the mechanisms underlying protective immunity following infection with Leishmania spp. are relatively well understood and because antigens are highly conserved between species. Proof-of-concept has been demonstrated with crude vaccine preparations, particularly when applied as a therapy. Traditional vaccination against CL by inoculating exudate in inconspicuous body areas produces self-healing lesions. Vaccination trials with CL promastigote preparations had efficacies in protecting against initial infections ranging from $0 \%$ to $75 \%$ (77). Therapeutically, killed vaccines when used with chemotherapy had increased efficacy over drug alone. Killed L. major together with Mycobacterium bovis bacillus Calmette-Guérin (BCG) was used to treat post kala-azar dermal leishmaniasis $(78,79)$, and a killed parasite vaccine is registered in Brazil to treat drug-refractory $\operatorname{ML}(29,80)$.

Acquired immunity directed toward Leishmania spp. is mediated by $\mathrm{T}$ cells (81-84). Specifically, $\mathrm{CD}^{+} \mathrm{T}$ cells are crucial for host defense, and mouse strains that are resistant to infection with Leishmania spp. develop a dominant Th1 response. Interfering with this response increases susceptibility to infection (85-88). In addition, IFN- $\gamma$-producing cells are associated with healing. In patients with VL, there is a direct correlation between IL-10 production and disease (89). Experimental animals can be protected against leishmaniasis using defined antigens (90), but few studies have used clinically relevant adjuvants. Indeed, the lack of safe and effective $\mathrm{T}$ cell adjuvants has been a major roadblock to the development of a vaccine to protect against infection with Leishmania spp. Approved adjuvants alum and squalene induce potent antibody responses, which do not seem to mediate protection, and only weak Th1 responses. Protection against experimental leishmaniasis requires induction of IL-12 by APCs, achieved via stimulation of TLR4, TLR9, TLR7, or TLR8, and protection against experimental leishmaniasis requires TLR signaling and/or IL-1/IL-18 signaling (91, 92). A three-protein fusion, Leish-111f, protects against CL and VL in mouse, hamster, and monkey models of these diseases (93-96), and a vaccine formulated in monophosphoryl lipid A is being evaluated in combined immuno- and chemotherapy trials (97).

Ideal anti-leishmanial vaccines should be safe, affordable, effective against multiple Leishmania spp., and effective as either a prophylactic or therapeutic. They should be based on recombinant antigens to provide for manufacturing consistency and have a clear path toward standardization and regulatory approval. Effective vaccines might be developed within the next 5-10 years. Their potential as therapeutics is particularly attractive, given the problems current therapies have of toxicity, expense, and tendency toward drug resistance (98). 


\section{Genomes, metabolism, and drug targets}

As indicated earlier, each kinetoplastid has more than 8,000 genes with more than 6,000 orthologs in common. L. major has the fewest genes and T. cruzi the most, with the differences primarily due to large gene families. In addition to their common core genome, they have a similar unusual genomic organization (99). Most of their orthologous genes occur in clusters in the same order (i.e., they are syntenic) and on the same DNA strand. This organization mirrors their unusual characteristics of cotranscription and processing of adjacent gene transcripts by coordinated polyadenylation of the upstream transcript and capping by spliced leader addition to the downstream transcript. Their genomic organizations primarily differ in the arrangement of the syntenic clusters, which results in different chromosome numbers and sizes (99). The differences in gene content primarily localize to the syntenic cluster boundaries and to chromosome ends. The key gene content differences reflect critical features of these pathogens. T. brucei subspecies have numerous VSG-encoding genes in subtelomeric clusters and in minichromosomes reflecting their antigenic variation (99). A large proportion of the T. cruzi genome contains clusters of large gene families of surface proteins described above. These trans-sialidase, mucin, and MASP gene families might function in immune evasion and adaptation to an intracellular environment. They are expressed in the mammalian life cycle stages and are among the strongest targets of host immune responses, but their abundance and diversity might present problems as vaccine candidates. Leishmania spp. have a simpler genome but also have the ability to amplify genomic regions. They contain genes for synthesis of complex surface glycoconjugates that are likely to provide for survival in the macrophage phagolysosome.

The capacity for homologous recombination has been exploited for experimental genetic manipulation of kinetoplastids to reveal gene function (100). All T. brucei subspecies and some Leishmania spp. possess RNAi ability, the function of which is uncertain, especially since it is dispensed within other Leishmania spp. and T. cruzi. Kinetoplastids have distinctive molecular processes that include adding an unusually capped $39 \mathrm{nt}$ sequence to the $5^{\prime}$ end of all mRNAs, reprogramming most mitochondrial mRNA sequences by RNA editing (101), and relying heavily on RNA turnover and translational level control rather than transcription initiation to regulate gene expression. T. brucei expresses only one of several VSG expression sites at any time, periodically switches expression to a different site, and employs complex recombinations among its more than 1,000 VSG-encoding genes and pseudogenes to generate a staggering repertoire of antigenic variants $(102,100)$. T. cruzi might undergo analogous recombination processes. These gene families, distinct molecular processes, as well as other factors yet to be discovered are potential new drug targets.

Analysis of the genomes of L. major, T. cruzi, and T. brucei, the three trypanosomatids (also known as TriTryp) (103), has revealed many common core metabolic functions as well as other pathways that might be specific adaptations to environments associated with life in their respective insect and vertebrate hosts. For example, only L. major seems capable of hydrolyzing disaccharides, possibly because the sandfly vectors of $L$. major feed on nectar and honeydew. Likewise, only T. cruzi has the potential to convert histidine to glutamate (104), reflecting the abundance of histidine in the excreta and hemolymph of its vector. Similarly, only T. cruzi lacks de novo pathways for polyamine biosynthesis, since polyamines can be obtained from the vector's excreta or from the host cytoplasm.
T. cruzi therefore lacks ornithine decarboxylase, the enzyme that mediates the first step in the polyamine biosynthesis pathway, which is the target of the drug eflornithine used to treat second-stage HAT caused by infection with T.b. gambiense (105). Other aspects of these fascinating metabolic adaptations, including how lateral gene transfer from prokaryotes might have shaped metabolism, are reviewed elsewhere $(103,106,107)$.

The completion of the TriTryp genomes offers unparalleled opportunities for the identification of much-needed novel drug targets (103). New targets have already emerged from genome analyses as well as phenotypic screens (108). In an ideal world, these would be common to all three disease-causing pathogens, sufficiently different from the mammalian host or unique to the parasite, and certainly essential for growth or survival of the parasite during the mammalian stages of its life cycle $(109,110)$. Some candidates are to be found in biosynthetic pathways for fatty acids (111), glycosylphosphatidylinositol anchors $(112,113)$, ergosterol and isoprenoids (114), as well as in the metabolism and functions of folates, pterins $(115,116)$, and trypanothione (117). Other promising areas for intervention include protein farnesyl transferases (118), cysteine proteases (108), $N$-myristoyltransferase (119), tubulin biosynthesis (120), S-adenosylmethionine and polyamine metabolism (105), purine salvage (121), protein kinases (122), DNA topoisomerases (123), and RNA-editing enzymes (124, $125)$. To further exploit the TriTryp genomes, the Special Programme for Research and Training in Tropical Diseases (TDR) has recently established the TDR Targets Database, in which the genes from these and other pathogens can be queried and ranked according to different "druggability" criteria (http://tdrtargets.org/).

Identification and characterization of molecular targets is merely a first step. Targets need to be validated as essential for parasite growth or survival using gene knockout or knockdown technologies and/or using highly specific small molecule inhibitors (110). Current estimates suggest that about $8 \%-12 \%$ of genes in mammalian, insect, helminth, and fungal genomes are druggable, that is, able to bind drug-like small molecules (126). Validating as druggable approximately 800 genes per parasite is a formidable but feasible challenge, even if other targets and pathogenesis determinants are discovered in the approximately $50 \%$ of hypothetical proteins in these genomes. However, since drug discovery and development is a risky and expensive undertaking, genetically and/or chemically validated targets also need to be rigorously assessed for chances of success by ranking against additional criteria such as druggability, assay feasibility, toxicity, and potential for the emergence of drug resistance $(108,127,110)$.

\section{Perspective and key issues}

New tools and efforts are needed to combat diseases caused by infection with a kinetoplastid. The diagnostics are inadequate, and in some cases primitive, the drug arsenal is ancient, blunt, and dangerous, and vaccines are essentially nonexistent. However, the progress in understanding kinetoplastid pathogens and their effects on their hosts, fueled by advances in technologies and increased public awareness, makes this a propitious time to develop the needed tools and interventions. Indeed, the elimination of HAT and Chagas disease as public health problems has been set as a goal by the WHO (128), and the elimination of VL, at least from the Indian subcontinent, is considered technically feasible and operationally achievable (129). Ironically, kinetoplastid diseases of livestock (e.g., trypanosomiasis in cattle) and domestic animals 
(e.g., leishmaniasis in dogs) might be a key incentive for developing interventions for human diseases.

The committed research community has responded by creating public-private partnerships (e.g., the Drugs for Neglected Diseases initiative [http://www.dndi.org] and the Foundation for Innovative Diagnostics [http://www.finddiagnostics.org]), research consortia (e.g., the Consortium for Parasitic Drug Development, the Trypanosome Drug Development Consortium, and Drug Discovery at Dundee [http://www.drugdiscovery.dundee.ac.uk]), and nongovernmental organizations (e.g., the Institute for OneWorld Health [http://www.oneworldhealth.org]) to generate drugs and diagnostics. Systematic efforts are being made to identify potential drug targets (http://www.tdrtargets.org/) as a prelude to target validation, development of drug screening assays, and testing against compound libraries (Collaborative Drug Discovery [http://www. collaborativedrug.com/]), and there are efforts to identify new diagnostics and develop vaccines where feasible. Multiple sustainable strategies for disease surveillance, vector control, treatment of infected patients, and immunization, all integrated by policies that span national borders, are also needed to achieve the goal of elimination of these diseases as public health threats $(20,130)$. The resultant reduction of human suffering and death and the associated poverty would be an enormous accomplishment.

There are challenges to achieving the above goals, but current technologies indicate that there are solutions. Post-genomic bioinformatic and experimental research can identify candidate diagnostics, drug targets, vaccine candidates, and pathogenic processes. Realistically, such diagnostics need to be non-invasive, inexpensive, rapid, and usable at remote and resource-poor sites. They must discriminate among pathogens and type of disease, not only to enable selection and monitoring of treatment, but also to be useful in drug and vaccine trials and surveillance. Immunodiagnostics need to contend with the complexities that each kinetoplastid disease presents, including antigenic variation, immune dysfunction, biodiversity, co-infection (especially with HIV), and poor nutritional status. Some of these factors, and low parasite numbers (especially during the chronic phases of disease) and location in deep tissues such as the CNS, heart muscle, liver, and spleen complicate detection of pathogens. Biomarker identifica- tion using mass spectrometry and genome databases, combined with new reagent and platform approaches, promises to deliver the needed diagnostics with the required product profiles (131). These analyses can also elucidate aspects of disease that can guide the development of novel therapeutic approaches.

New effective, safe, and affordable drugs, preferably oral, are needed for all kinetoplastids. Indeed, more than one new drug is needed for each so that combination therapy can be employed to avoid drug resistance and to provide backup drugs when resistance emerges. The research consortia have organized to provide the multidisciplinary requirements needed for drug development. Resources are needed to enable the coordination of these researchers' activities and to incorporate the expertise of the for-profit drug development enterprises. Such activities have the ability to lead to the needed drugs.

Kinetoplastid human pathogens are exquisitely adapted to their hosts and evade immune elimination by antigenic variation, intracellular and organ sequestration, and alteration of immune responsiveness. There is no effective immune response mounted by individuals with HAT and the disease is invariably fatal; the immune responses to T. cruzi and Leishmania spp. tend to control infection rather than eliminate it, thus resulting in pathology. Dissection of immune responses and pathogenesis will lead to the identification of antigens that can be used to prevent disease rather than prevent infection and to provide better diagnostics.

\section{Acknowledgments}

Research in Ken Stuart's lab is supported by grants from the NIH. Alan H. Fairlamb is co-director of the Drug Discovery Unit at Dundee and is supported by the Wellcome Trust. Jim McKerrow's lab is supported by The Sandler Family Supporting Foundation and National Institute of Allergy and Infectious Diseases Tropical Disease Research Unit grant AI35707. Research in Rick Tarleton's lab is supported by grants from the NIH.

Address correspondence to: Ken Stuart, Seattle Biomedical Research Institute, 307 Westlake Avenue N, Suite 500, Seattle, Washington, USA. Phone: (206) 256-7316; Fax: (206) 256-7229; E-mail: ken.stuart@sbri.org.
1. Burri, C., and Brun, R. 2003. Human African trypanosomiasis. In Manson's tropical diseases. G.C. Cook and A.I. Zumla, editors. 21st edition. W.B Saunders/Elsevier. Edinburgh, United Kingdom. 1303-1323.

2. [No authors listed]. 2006. Human African trypanosomiasis (sleeping sickness): epidemiological update. Wkly. Epidemiol. Rec. 81:71-80.

3. Radwanska, M., et al. 2002. The serum resistanceassociated gene as a diagnostic tool for the detection of Trypanosoma brucei rhodesiense. Am.J. Trop. Med. Hyg. 67:684-690

4. Radwanska, M., et al. 2002. Novel primer sequences for polymerase chain reaction-based detection of Trypanosoma brucei gambiense. Am. J. Trop. Med. Hyg. 67:289-295.

5. Magnus, E., Vervoort, T., and Van Meirvenne, N 1978. A card-agglutination test with stained trypanosomes (C.A.T.T.) for the serological diagnosis of T. B. gambiense trypanosomiasis. Ann. Soc. Belg. Med. Trop. 58:169-176.

6. Deborggraeve, S., et al. 2006. Molecular dipstick test for diagnosis of sleeping sickness. J. Clin. Microbiol. 44:2884-2889.

7. Xong, H.V., et al. 1998. A VSG expression site-associated gene confers resistance to human serum in
Trypanosoma rhodesiense. Cell. 95:839-846

8. Welburn, S.C., et al. 2001. Identification of human-infective trypanosomes in animal reservoir of sleeping sickness in Uganda by means of serum-resistance-associated (SRA) gene. Lancet. 358:2017-2019.

9. Lejon, V., et al. 2002. IgM quantification in the cerebrospinal fluid of sleeping sickness patients by a latex card agglutination test. Trop. Med. Int. Health. 7:685-692.

10. [Anonymous]. 1998. Control and surveillance of African trypanosomiasis. Report of a WHO Expert Committee. World Health Organ. Tech. Rep. Ser. 881:1-114.

11. Young, C., Losikoff, P., Chawla, A., Glasser, L., and Forman, E. 2007. Transfusion-acquired Trypanosoma cruzi infection. Transfusion. 47:540-544.

12. [Anonymous]. 2006. Chagas disease after organ transplantation - Los Angeles, California, 2006. MMWR Morb. Mortal. Wkly. Rep. 55:798-800.

13. Gurtler, R.E., Segura, E.L., and Cohen, J.E. 2003. Congenital transmission of Trypanosoma cruzi infection in Argentina. Emerg. Infect Dis. 9:29-32.

14. Benchimol Barbosa, P.R. 2006. The oral transmission of Chagas' disease: an acute form of infection responsible for regional outbreaks. Int. J. Cardiol.
112:132-133.

15. Tarleton, R.L. 2003. Chagas disease: a role for autoimmunity? Trends Parasitol. 19:447-451.

16. Andrade, L.O., and Andrews, N.W. 2005. The Trypanosoma cruzi-host-cell interplay: location, invasion, retention. Nat. Rev. Microbiol. 3:819-823.

17. Burleigh, B.A. 2005. Host cell signaling and Trypanosoma cruzi invasion: do all roads lead to lysosomes? Sci. STKE. 2005:e36.

18. Combs, T.P., et al. The adipocyte as an important target cell for Trypanosoma cruzi infection. J. Biol. Chem. 280:24085-24094.

19. Tarleton, R.L, Reithinger, R., Urbina, J.A., Kitron, U., and Gurtler, R.E. 2007. The challenges of Chagas disease - grim outlook or glimmer of hope. PLoS Med. 4:e332.

20. Gürtler, R.E., Kitron, U., Cecere, M.C., Segura, E.L., and Cohen, J.E. 2007. Sustainable vector control and management of Chagas disease in the Gran Chaco, Argentina. Proc. Natl. Acad. Sci. U. S. A. 104:16194-16199.

21. Pirard, M., Iihoshi, N., Boelaert, M., Basanta, P., Lopez, F., and Van der Stuyft, P. 2005. The validity of serologic tests for Trypanosoma cruzi and the effectiveness of transfusional screening strategies in a hyperendemic region. Transfusion. 45:554-561. 
22. Avila, H.A., et al. 1993. Detection of Trypanosoma cruzi in blood specimens of chronic chagasic patients by polymerase chain reaction amplification of kinetoplast minicircle DNA: comparison with serology and xenodiagnosis. J. Clin. Microbiol. 31:2421-2426.

23. Grevelink, S.A., and Lerner, E.A. 1996. Leishmaniasis. J Am Acad Dermatol. 34:257-272.

24. Marsden, P.D. 1990. Mucocutaneous leishmaniasis. BMJ 301:656-657.

25. Ramesh, V., and Mukherjee, A. 1995. Post-kala-azar dermal leishmaniasis. Int. J. Dermatol. 34:85-91.

26. Zijlstra, E.E., Musa, A.M., Khalil, E.A., el-Hassan, I.M., and El-Hassan, A.M. 2003. Post-kala-azar dermal leishmaniasis. Lancet Infect. Dis. 3:87-98.

27. Albrecht, H. 1998. Leishmaniosis - new perspectives on an underappreciated opportunistic infection. AIDS. 12:2225-2226.

28. Ambroise-Thomas, P. 2001. Parasitic diseases and immunodeficiencies. Parasitology. 122(Suppl.): S65-S71.

29. Genaro, O., et al. 1996. Vaccine for prophylaxis and immunotherapy, Brazil. Clin. Dermatol. 14:503-512.

30. McConville, M.J., de Souza, D., Saunders, E., Likic, V.A., and Naderer, T. 2007. Living in a phagolysosome; metabolism of Leishmania amastigotes. Trends Parasitol. 23:368-375.

31. Denkers, E.Y., and Butcher, B.A. 2005. Sabotage and exploitation in macrophages parasitized by intracellular protozoans. Trends Parasitol. 21:35-41.

32. Grazia, C.M., Sutterwala, F.S., Trinchieri, G., Mosser, D.M., and Ma, X. 2001. Suppression of Il-12 transcription in macrophages following Fc gamma receptor ligation. J. Immunol. 166:4498-4506.

33. Marth, T., and Kelsall, B.L. 1997. Regulation of interleukin-12 by complement receptor 3 signaling. J. Exp. Med. 185:1987-1995.

34. Ghalib, H.W., et al. 1995. IL-12 enhances Th1-type responses in human Leishmania donovani infections. J. Immunol. 154:4623-4629.

35. Reed, S.G. 1996. Diagnosis of leishmaniasis. Clin. Dermatol. 14:471-478.

36. Sadeghian, G., Momeni, A., Siadat, A.H., and Usefi, P. 2006. Evaluation of leishmanin skin test and its relationship with the clinical form and duration of cutaneous leishmaniasis. Dermatol. Online J. 12:3.

37. Burns, J.M., Jr., et al. 1993. Molecular characterization of a kinesin-related antigen of Leishmania chagasi that detects specific antibody in African and American visceral leishmaniasis. Proc. Natl. Acad. Sci. U. S. A. 90:775-779.

38. Houghton, R.L., et al. 1998. A cloned antigen (recombinant K39) of Leishmania chagasi diagnostic for visceral leishmaniasis in human immunodeficiency virus type 1 patients and a prognostic indicator for monitoring patients undergoing drug therapy. J. Infect. Dis. 177:1339-1344.

39. Chava, A.K., Chatterjee, M., Sharma, V., Sundar, S. and Mandal, C. 2004. Variable degree of alternative complement pathway-mediated hemolysis in Indian visceral leishmaniasis induced by differential expression of 9-O-acetylated sialoglycans. J. Infect. Dis. 189:1257-1264.

40. Reithinger, R., and Dujardin, J.C. 2007. Molecular diagnosis of leishmaniasis: current status and future applications. J. Clin. Microbiol. 45:21-25.

41. da Costa, R.T., et al. 2003. Standardization of a rapid immunochromatographic test with the recombinant antigens $\mathrm{K} 39$ and $\mathrm{K} 26$ for the diagnosis of canine visceral leishmaniasis. Trans. R. Soc. Trop. Med. Hyg. 97:678-682.

42. De Luca, P.M., et al. 2003. Randomized, doubleblind, placebo-controlled study on the immunogenicity of the leishmanin skin test. Trans. R. Soc. Trop. Med. Hyg. 97:709-712.

43. Mazurek, G.H., et al. 2005. Guidelines for using the QuantiFERON-TB Gold test for detecting Mycobacterium tuberculosis infection, United States.
MMWR Recomm. Rep. 54:49-55.

44. Burri, C., Stich, G., and Brun, R. 2004. Current chemotherapy of human african trypanosomiasis. In Trypanosomiasis. I. Maudlin, P.H. Holmes, and M.A. Miles, editors. CABI Publishing. Wallingford, U.K. 45. Barrett, M.P., Boykin, D.W., Brun, R., and Tidwell, R.R. 2007. Human African trypanosomiasis: pharmacological re-engagement with a neglected disease. Br. J. Pharmacol. In press.

46. Brun, R., Schumacher, R., Schmid, C., Kunz, C., and Burri, C. 2001. The phenomenon of treatment failures in Human African Trypanosomiasis. Trop. Med. Int. Health. 6:906-914.

47. Burri, C., Baltz, T., Giroud, C., Doua, F., Welker, H.A., and Brun, R. 1993. Pharmacokinetic properties of the trypanocidal drug melarsoprol. Chemotherapy. 39:225-234.

48. Schmid, C., Nkunku, S., Merolle, A., Vounatsou, P. and Burri, C. 2004. Efficacy of 10-day melarsoprol schedule 2 years after treatment for late-stage gambiense sleeping sickness. Lancet. 364:789-790.

49. Bisser, S., et al. 2007. Equivalence trial of melarsoprol and nifurtimox monotherapy and combination therapy for the treatment of second-stage Trypanosoma brucei gambiense sleeping sickness. J. Infect. Dis. 195:322-329.

50. Torr, S.J., Maudlin, I., and Vale, G.A. 2007. Less is more: restricted application of insecticide to cattle to improve the cost and efficacy of tsetse control. Med Vet. Entomol. 21:53-64.

51. Kgori, P.M., Modo, S., and Torr, S.J. 2006. The use of aerial spraying to eliminate tsetse from the Okavango Delta of Botswana. Acta Trop. 99:184-199.

52. Castro, J.A., de Mecca, M.M., and Bartel, L.C. 2006 Toxic side effects of drugs used to treat Chagas' disease (American trypanosomiasis). Hum. Exp. Toxicol. 25:471-479.

53. Sosa, E.S., et al. 1998. Efficacy of chemotherapy with benznidazole in children in the indeterminate phase of Chagas' disease. Am. J. Trop. Med. Hyg. 59:526-529.

54. Viotti, R., Vigliano, C., Armenti, H., and Segura, E. 1994. Treatment of chronic Chagas' disease with benznidazole: clinical and serologic evolution of patients with long-term follow-up. Am. Heart J. 127:151-162.

55. Viotti, R., et al. 2006. Long-term cardiac outcomes of treating chronic Chagas disease with benznidazole versus no treatment: a nonrandomized trial. Ann. Intern. Med 144:724-734.

56. de Castro, A.M., Luquetti, A.O., Rassi, A., Chiari, E., and Galvao, L.M. 2006. Detection of parasitemia profiles by blood culture after treatment of human chronic Trypanosoma cruzi infection. Parasitol. Res. 99:379-383.

57. Molina, J., et al. 2000. Activities of the triazole derivative SCH 56592 (posaconazole) against drug-resistant strains of the protozoan parasite Trypanosoma (Schizotrypanum) cruzi in immunocompetent and immunosuppressed murine hosts. Antimicrob. Agents Chemother. 44:150-155.

58. Engel, J.C., Doyle, P.S., Hsieh, I., and McKerrow, J.H. 1998. Cysteine protease inhibitors cure an experimental Trypanosoma cruzi infection. J Exp. Med. 188:725-734.

59. Doyle, P.S., Zhou, Y.M., Engel, J.C., and McKerrow, J.H. 2007. A cysteine protease inhibitor cures Chagas' disease in an immunodeficient-mouse model of infection. Antimicrob. Agents Chemother. 51:3932-3939.

60. Dias, J.C., Silveira, A.C., and Schofield, C.J. 2002. The impact of Chagas disease control in Latin America: a review. Mem. Inst. Oswaldo Cruz. 97:603-612.

61. Gurtler, R.E., et al. 2004. Effectiveness of residual spraying of peridomestic ecotopes with deltamethrin and permethrin on Triatoma infestans in rural western Argentina: a district-wide randomized trial. Bull. World. Health Organ. 82:196-205.

62. Picollo, M.I., et al. 2005. High resistance to pyre- throid insecticides associated with ineffective field treatments in Triatoma infestans (Hemiptera: Reduviidae) from Northern Argentina. J. Med. Entomol. 42:637-642.

63. Cohen, J.E., and Gurtler, R.E. 2001. Modeling household transmission of American trypanosomiasis. Science. 293:694-698.

64. Kroeger, A., Villegas, E., Ordonez-Gonzalez, J., Pabon, E., and Scorza, J.V. 2003. Prevention of the transmission of Chagas' disease with pyrethroidimpregnated materials. Am. J. Trop. Med. Hyg. 68:307-311.

65. Reithinger, R., Ceballos, L., Stariolo, R., Davies, C.R., and Gurtler, R.E. 2006. Extinction of experimental Triatoma infestans populations following continuous exposure to dogs wearing deltamethrin-treated collars. Am. J. Trop. Med. Hyg. 74:766-771.

66. Tarleton, R.L. 2007. Immune system recognition of Trypanosoma cruzi. Curr. Opin. Immunol. 19:430-434.

67. Martin, D.L., et al. 2006. CD8+ T-Cell responses to Trypanosoma cruzi are highly focused on strainvariant trans-sialidase epitopes. PLoS Pathog. 2:e77.

68. Gurtler, R.E., et al. 2007. Domestic dogs and cats as sources of Trypanosoma cruzi infection in rural northwestern Argentina. Parasitology. 134:69-82.

69. Olliaro, P.L., et al. 2005. Treatment options for visceral leishmaniasis: a systematic review of clinical studies done in India, 1980-2004. Lancet. Infect. Dis. 5:763-774.

70. Sundar, S., et al. 2003. Single-dose liposomal amphotericin B in the treatment of visceral leishmaniasis in India: a multicentre study. Clin. Infect. Dis. 37:800-804.

71. Bern, C., et al. 2006. Liposomal amphotericin B for the treatment of visceral leishmaniasis. Clin. Infect. Dis. 43:917-924.

72. Sundar, S., Jha, T.K., Thakur, C.P., Sinha, P.K., and Bhattacharya, S.K. 2007. Injectable paromomycin for Visceral leishmaniasis in India. N. Engl. J. Med. 356:2571-2581.

73. Armijos, R.X., Weigel, M.M., Calvopina, M., Mancheno, M., and Rodriguez, R. 2004. Comparison of the effectiveness of two topical paromomycin treatments versus meglumine antimoniate for New World cutaneous leishmaniasis. Acta Trop. 91:153-160.

74. Thakur, C.P., et al. 2000. Treatment of visceral leishmaniasis with injectable paromomycin (aminosidine). An open-label randomized phase-II clinical study. Trans. R. Soc. Trop. Med. Hyg. 94:432-433.

75. Bhattacharya, S.K., et al. 2007. Phase 4 trial of miltefosine for the treatment of Indian visceral leishmaniasis. J. Infect. Dis. 196:591-598.

76. Soto, J., and Berman, J. 2006. Treatment of New World cutaneous leishmaniasis with miltefosine. Trans. R. Soc. Trop. Med. Hyg. 100(Suppl. 1):S34-S40.

77. Engers, H.D., Bergquist, R., and Modabber, F. 1996. Progress on vaccines against parasites. Dev. Biol Stand. 87:73-84.

78. Khalil, E.A., et al. 2000. Autoclaved Leishmania major vaccine for prevention of visceral leishmaniasis: a randomised, double-blind, BCG-controlled trial in Sudan. Lancet. 356:1565-1569.

79. Khalil, E.A., et al. 2000. Safety and immunogenicity of an autoclaved Leishmania major vaccine. East. Afr. Med. J. 77:468-470.

80. Mayrink, W., et al. 1992. Immunotherapy as a treatment of American cutaneous leishmaniasis: preliminary studies in Brazil. Parassitologia. 34:159-165.

81. Jones, D.E., Elloso, M.M., and Scott, P. 1998. Host susceptibility factors to cutaneous leishmaniasis. Front. Biosci. 3:D1171-D1180.

82. Lohoff, M., Gessner, A., Bogdan, C., and Rollinghoff, M. 1998. The Th1/Th2 paradigm and experimental murine leishmaniasis. Int Arch. Allergy. Immunol. 115:191-202.

83. Reed, S.G., and Scott, P. 1993. T-cell and cytokine 
responses in leishmaniasis. Curr. Opin. Immunol. 5:524-531.

84. Reiner, S.L., and Locksley, R.M. 1995. The regulation of immunity to Leishmania major. Annu. Rev Immunol. 13:151-177.

85. Gorczynski, R.M. 1982. Nature of resistance to leishmaniasis in experimental rodents. Dev. Comp. Immunol. 6:199-207.

86. Guler, M.L., et al. 1996. Genetic susceptibility to Leishmania: IL-12 responsiveness in TH1 cell development. Science. 271:984-987.

87. Launois, P., Himmelrich, H., Tacchini-Cottier, F., Milon, G., and Louis, J.A. 1999. New insight into the mechanisms underlying Th2 cell development and susceptibility to Leishmania major in BALB/C mice. Microbes Infect. 1:59-64.

88. Scharton-Kersten, T., Afonso, L.C., Wysocka, M., Trinchieri, G., and Scott, P. 1995. IL-12 is required for natural killer cell activation and subsequent $\mathrm{T}$ helper 1 cell development in experimental leishmaniasis. J. Immunol. 154:5320-5330.

89. Nylen, S., and Sacks, D. 2007. Interleukin-10 and the pathogenesis of human visceral leishmaniasis. Trends Immunol. 28:378-384.

90. Coler, R.N., and Reed, S.G. 2005. Second-generation vaccines against leishmaniasis. Trends Parasitol. 21:244-249.

91. Hawn, T.R., et al. 2002. Leishmania major activates IL-1 alpha expression in macrophages through a MyD88-dependent pathway. Microbes Infect. 4:763-771.

92. Kropf, P., et al. 2004. Toll-like receptor 4 contributes to efficient control of infection with the protozoan parasite Leishmania major. Infect Immun 72:1920-1928.

93. Campos-Neto, A., et al. 2001. Protection against cutaneous leishmaniasis induced by recombinant antigens in murine and nonhuman primate models of the human disease. Infect. Immun. 69:4103-4108.

94. Coler, R.N., Goto, Y., Bogatzki, L., Raman, V., and Reed, S.G. 2007. Leish-111f, a Recombinant Polyprotein Vaccine That Protects against Visceral Leishmaniasis by Elicitation of CD4+ T Cells. Infect. Immun. 75:4648-4654.

95. Coler, R.N., et al. 2002. Immunization with a polyprotein vaccine consisting of the T-Cell antigens thiol-specific antioxidant, Leishmania major stress-inducible protein 1, and Leishmania elongation initiation factor protects against leishmaniasis. Infect. Immun. 70:4215-4225.

96. Skeiky, Y.A., et al. 2002. Protective efficacy of a tandemly linked, multi-subunit recombinant leishmanial vaccine (Leish-111f) formulated in MPL adjuvant. Vaccine. 20:3292-3303.

97. Ghalib, H., and Modabber, F. 2007. Consultation meeting on the development of therapeutic vaccines for post kala azar dermal leishmaniasis. Kinetoplastid Biol. Dis. 6:7.

98. Croft, S.L., Sundar, S., and Fairlamb, A.H. 2006. Drug resistance in leishmaniasis. Clin. Microbiol. Rev. 19:111-126.

99. El-Sayed, N.M., et al. 2005. Comparative genomics of trypanosomatid parasitic protozoa. Science. 309:404-409.

100.Barry, D., et al. 2007. Trypanosomes: after the genome. Horizon Scientific Press. Norfolk, United King dom. 423 pp.

101.Stuart, K.D., Schnaufer, A., Ernst, N.L., and Panigrahi, A.K. 2005. Complex management: RNA editing in trypanosomes. Trends Biochem. Sci. 30:97-105.

102. Borst, P., et al. 1997. Mechanisms of antigenic variation in African trypanosomes. Behring. Inst. Mitt. $1-15$.

103.Berriman, M., et al. 2005. The genome of the african trypanosome Trypanosoma brucei. Science. 309:416-422.

104.Atwood, J.A., 3rd, et al. 2005. The Trypanosoma cruzi proteome. Science. 309:473-476.

105.Heby, O., Persson, L., and Rentala, M. 2007. Targeting the polyamine biosynthetic enzymes: a promising approach to therapy of African sleeping sickness, Chagas' disease, and leishmaniasis. Amino Acids. 33:359-366.

106.Opperdoes, F.R., and Coombs, G.H. 2007. Metabolism of Leishmania: proven and predicted. Trends Parasitol. 23:149-158.

107. Ginger, M.L., Fairlamb, A.H., and Opperdoes, F.R. 2007. Comparative genomics of trypanosome metabolism. In Trypanosomes: after the genome. D. Barry, R. McCulloch, J. Mottram, and A. AcostaSerrano, editors. Horizon Bioscience. Wynondham, United Kingdom. 373-416.

108. Renslo, A.R., and McKerrow, J.H. 2006. Drug discovery and development for neglected parasitic diseases. Nat. Chem. Biol. 2:701-710.

109. Fairlamb, A.H. 2003. Target discovery and validation with special reference to trypanothione. In Drugs against parasitic diseases: RひDD methodologies and issues. A.H. Fairlamb, R.G. Ridley, and H.J. Vial, editors TDR Publications. Geneva, Switzerland. 107-118.

110.Frearson, J.A., Wyatt, P.A., Gilbert, I.H., and Fairlamb, A.H. 2007. Target assessment for anti-parasitic drug discovery. Trends Parasitol. 23:589-595.

111.Lee, S.H., Stephens, J.L., and Englund, P.T. 2007. A fatty-acid synthesis mechanism specialized for parasitism. Nat. Rev. Microbiol. 5:287-297.

112.de Macedo, C.S., Shams-Eldin, H., Smith, T.K. Schwarz, R.T., and Azzouz, N. 2003. Inhibitors of glycosyl-phosphatidylinositol anchor biosynthesis. Biochimie. 85:465-472.

113.Ferguson, M.A.J., et al. 1999. The GPI biosynthetic pathway as a therapeutic target for African sleeping sickness. Biochim. Biophys. Acta. 1455:327-340.

114.Urbina, J.A. 2003. New chemotherapeutic approaches for the treatment of Chagas disease (American Trypanosomiasis). Expert Opinion on Therapeutic Patents. 13:661-669.

115. Nare, B., Luba, J., Hardy, L.W., and Beverley, S.M. 1997. New approaches to Leishmania chemotherapy: Pteridine reductase 1 (PTR1) as a target and modulator of antifolate sensitivity. Parasitology. 114:S101-S110.

116. Ouellette, M., et al. 2002. Pterin transport and metabolism in Leishmania and related trypanosomatid parasites. Int. J. Parasitol. 32:385-398.

117. Krauth-Siegel, R.L., Bauer, H., and Schirmer, H. 2005. Dithiol proteins as guardians of the intracellular redox milieu in parasites: old and new drug targets in trypanosomes and malaria-causing plasmodia. Angew. Chem. Int. Ed. Engl. 44:690-715.

118.Eastman, R.T., Buckner, F.S., Yokoyama, K., Gelb, M.H., and Van Voorhis, W.C. 2006. Thematic review series: lipid posttranslational modifications. Fight- ing parasitic disease by blocking protein farnesylation. J. Lipid Res. 47:233-240.

119.Panethymitaki, C., et al. 2006. Characterization and selective inhibition of myristoyl-CoA: protein $\mathrm{N}$-myristoyltransferase from Trypanosoma brucei and Leishmania major. Biochem. J. 396:277-285.

120. Werbovetz, K.A. 2000. Target-based drug discovery for malaria, leishmaniasis, and trypanosomiasis. Curr. Med. Chem. 7:835-860.

121.El Kouni, M.H. 2003. Potential chemotherapeutic targets in the purine metabolism of parasites. Pharmacol. Ther. 99:283-309.

122.Hammarton, T.C., Mottram, J.C., and Doerig, C. 2003. The cell cycle of parasitic protozoa: potential for chemotherapeutic exploitation. Prog. Cell Cycle Res. 5:91-101.

123. Balana-Fouce, R., Redondo, C.M., Perez-Pertejo, Y., Diaz-Gonzalez, R., and Reguera, R.M. 2006. Targeting atypical trypanosomatid DNA topoisomerase I. Drug Discov. Today. 11:733-740.

124.Deng, J., Ernst, N.L., Turley, S., Stuart, K.D., and Hol, W.G. 2005. Structural basis for UTP specificity of RNA editing TUTases from Trypanosoma brucei. EMBO J. 24:4007-4017.

125.Schnaufer, A., et al. 2001. An RNA ligase essential for RNA editing and survival of the bloodstream form of Trypanosoma brucei. Science. 291:2159-2162.

126.Hopkins, A.L., and Groom, C.R. 2002. The druggable genome. Nat. Rev. Drug Discov. 1:727-730.

127. Nwaka, S., and Hudson, A. 2006. Innovative lead discovery strategies for tropical diseases. Nat. Rev. Drug Discov. 5:941-955.

128. [Anonymous]. 2006. Development and evaluation of new diagnostic tests for human African trypanosomiasis. Wkly. Epidemiol. Rec. 81:59-60.

129. Bhattacharya, S.K., Sur, D., Sinha, P.K., and Karbwang, J. 2006. Elimination of leishmaniasis (kalaazar) from the Indian subcontinent is technically feasible and operationally achievable. Indian J. Med. Res. 123:195-196.

130.Enserink, M. 2007. Entomology. Welcome to Ethiopia's fly factory. Science. 317:310-313.

131.Agranoff, D., Stich, A., Abel, P., and Krishna, S. 2005. Proteomic fingerprinting for the diagnosis of human African trypanosomiasis. Trends Parasitol. 21:154-157.

132. [Anonymous]. 2002. Manson's tropical diseases. W.B. Saunders/Elsevier. Edinburgh, United Kingdom. 1864 pp.

133.Lane, R.P., and Crosskey, R.W. 1993. Medical insects and arachnids. Chapman \& Hall. London, United Kingdom. 723 pp.

134.[Anonymous]. 2004. The World Health Report 2004: changing history. WHO. Geneva, Switzerland. $167 \mathrm{pp}$.

135.Maudlin, I., Holmes, P.H., and Miles, M.A. 2004. The Trypanosomiases. CABI Publishing. Wallingford, United Kingdom. 632 pp.

136. Scientific Working Group. 2001. Report on African Trypanosomiasis (sleeping sickness). WHO. Geneva, Switzerland. 1-169.

137. Scientific Working Group 2004. Report on Leishmaniasis. WHO. Geneva, Switzerland. 137 pp.

138. Kuzoe, F.A.S., and Shofield, C.J. 2004. Strategic review of traps and targets of tsetse and African typanosomiasis control. WHO. Geneva, Switzerland. 58 pp. 